\title{
Survivin in brain tumors: an attractive target for immunotherapy
}

\author{
Masahito Katoh ${ }^{1}$, Rick Wilmotte ${ }^{1}$, Marie-Claude Belkouch ${ }^{1}$, Nicolas de Tribolet ${ }^{2}$, Gianpaolo Pizzolato ${ }^{3}$ and \\ Pierre-Yves Dietrich ${ }^{1}$ \\ ${ }^{1}$ Laboratory of Tumor Immunology, Division of Oncology; ${ }^{2}$ Department of Neurosurgery; \\ ${ }^{3}$ Division of Neuropathology, University Hospital of Geneva, Geneva, Switzerland
}

Key words: apoptosis inhibitor, brain tumor, immunotherapy, survivin, tumor antigen

\section{Summary}

Survivin, a member of the inhibitor of apoptosis proteins gene family, was recently shown to be expressed by tumors originating from different cell lineages. There are also cumulative evidences that spontaneous immune response against survivin derived epitopes may occur. Here, using RT-PCR, Western-blot analysis and immunohistochemistry, we show that survivin is widely expressed by gliomas, meningiomas and schwannomas, both in vitro and in vivo. These data indicate that survivin may serve as an attractive target for immunotherapies designed for brain tumors.

\section{Introduction}

Apoptosis is a complex program of cellular suicide, and inhibition of apoptosis is considered to be an important mechanism involved in cancer formation and progression by extending the life span of cells and thus favoring the accumulation of transforming mutations [1]. Survivin is a member of the inhibitor-ofapoptosis (IAP) family that blocks apoptosis pathways by inhibiting effector caspase molecules [2]. Whilst highly expressed in fetal tissues, survivin is generally not detectable in normal adult tissues with the exception of thymus and placenta [2]. In contrast, expression of survivin was reported in the majority of malignant tumors arising from the lung [3], the prostate [4], the skin [5], the colon [6], the pancreas [7], the breast [8], the stomach [9], the esophagus [10] and from hematopoietic cells [11]. Interestingly, expression of survivin was shown to be associated with an unfavorable prognosis of some cancers $[3,10,11]$, supporting the idea that apoptosis inhibition may contribute to tumor progression.

Recent data suggest that a significant fraction of human astrocytomas may also express survivin. Using semi-quantitative Western-blot analysis on frozen tumor tissues, Chakravarti et al. [12] reported that $80 \%$ of glioblastoma and $39 \%$ of not grade IV astrocytoma samples were indeed positive for survivin expression.
However, this approach does not clarify whether tumor cells themselves express survivin and to what extent non tumoral cells such as endothelial cells or infiltrating lymphocytes might contribute to the Western positivity. This is an important issue to explore considering that activated lymphocytes have recently been shown to express survivin [13]. Here, we provide evidence that glioma cells express survivin both in vitro and in vivo. Furthermore, survivin expression is not restricted to the astrocytic lineage, since most meningiomas and schwannomas are also survivin positive.

\section{Materials and methods}

\section{Patients}

Peripheral blood samples and tumor biopsies were collected during surgery from 76 patients with brain tumor at the Geneva University Hospital from March 1995 to February 2002. No prior treatment was administered before surgery, except in one case (Ge 133). There were 46 males and 30 females with a mean age of 48.7 years (range: 13-80 years) (Table 1).

\section{Tumor cell lines}

Melanoma cell line A375 and K562 cell line (a human erythroleukemia cell line) were obtained from ATCC. 
Table 1. Survivin mRNA expression in brain tumor patients (M: male, F: female)

\begin{tabular}{llrrrr}
\hline Diagnosis & $\begin{array}{l}\text { Number of } \\
\text { cases }\end{array}$ & M & F & Mean age (range) & $\begin{array}{l}\text { Expression } \\
\text { rate }(\%)\end{array}$ \\
\hline Glioblastoma & \multicolumn{1}{c}{23} & 13 & 10 & $55.6(18-80)$ & 91.3 \\
Anaplastic astrocytoma & 10 & 5 & 5 & $44.4(21-61)$ & 90.0 \\
Grade II astrocytoma & 9 & 7 & 2 & $36.3(15-58)$ & 66.7 \\
Grade I astrocytoma & 5 & 4 & 1 & $29.0(13-49)$ & 60.0 \\
Oligodendroglioma & 8 & 8 & 0 & $42.0(24-65)$ & 100.0 \\
Meningioma & 10 & 4 & 6 & $65.0(46-80)$ & 60.0 \\
Schwannoma & 11 & 5 & 6 & $47.0(19-75)$ & 100.0 \\
\hline
\end{tabular}

Human astrocytoma cell lines were derived from tumor biopsies ( 7 glioblastomas and 1 anaplastic astrocytoma) and maintained in culture as previously described [14].

\section{Detection of survivin mRNA}

Total RNA from frozen tumor and epileptic brain biopsies or from $10^{6}$ cells of tumor cell lines was isolated using RNeasy midi kit or RNeasy mini kit respectively (Qiagen, Hilden, Germany) following manufacturer's recommendations. RNA concentration was determined using spectrophotometry. Total RNA $(1 \mu \mathrm{g})$ was reverse transcribed using Supersript II (Invitrogen, Groningen, The Netherlands). $10 \%$ of the complementary cDNA was used for the PCR. PCR was done using Ready Mix ${ }^{\text {TM }}$ PCR reaction mix (Sigma, Buchs, Switzerland) in a final volume of $25 \mu l$ containing $1 \mu \mathrm{M}$ of each $5^{\prime}$ and $3^{\prime}$ primers (forward and reverse primers). The primer pair used for the detection of sur-

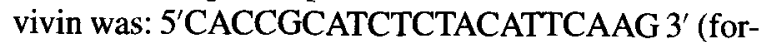
ward primer); 5'GAAGTGGTGCAGCCACTCTG $3^{\prime}$ (reverse primer). PCR conditions were as follows: $1 \mathrm{~min}$ at $94^{\circ} \mathrm{C}$ of initial denaturation, followed by 30 cycles of amplification $\left(30 \mathrm{~s}\right.$ at $94^{\circ} \mathrm{C}, 30 \mathrm{~s}$ at $58^{\circ} \mathrm{C}, 30 \mathrm{~s}$ at $72^{\circ} \mathrm{C}$ ) and a final extension step of $10 \mathrm{~min}$ at $72^{\circ} \mathrm{C}$. To check the quality of the cDNA, human $\beta$-actin cDNA amplification was performed. PCR products were resolved on a $1 \%$ agarose gel and stained with ethidium bromide. The melanoma cell line A375 was used as positive control. The generated PCR products were verified by sequencing.

\section{Western blot}

Human K562 cell line, human astrocytoma cell lines, Flu cytotoxic $\mathrm{T}$ cell lymphocytes (CTLs) (directed against M1 peptide: 58-66) and peripheral blood mononuclear cells (PBMC) were used for Western-blot analysis. Briefly, $10^{6}$ cells were lysed in a lysis buffer containing $25 \mathrm{mM}$ Tris- $\mathrm{HCl} \mathrm{pH} 7.5,75 \mathrm{mM} \mathrm{NaCl}$, $0.5 \%$ Nonidet $\mathrm{P} 40,0.25 \%$ sodium deoxycholate, 0.05 $\%$ SDS and the complete protease inhibitors set (Roche Diagnostics, Mannheim, Germany). The samples were denatured in $2 \times \mathrm{SDS}$ buffer at $95^{\circ} \mathrm{C}$ for $5 \mathrm{~min}$ then separated on a $10 \%$ SDS-polyacrylamide gel (SDS-PAGE) and transferred onto nitrocellulose membrane. Filters were incubated with an anti-human survivin antibody (R\&D Systems, Abingdon, United Kingdom) followed by horseradish peroxidase-conjugated antirabbit immunogloblin and developed using chemoluminescence detection kit (Amersham, Uppsala, Sweden).

\section{Immunohistochemistry}

A rabbit polyclonal IgG anti-human survivin antibody (R\&D system) was used to detect human survivin on brain tumor histological sections. Normal rabbit IgG was used as a negative control (R\&D systems). For immunohistochemical detection, the standard avidinbiotin peroxydase complex technique was carried out by using an LSAB Kit (Dako, Glostrup, Denmark). Sections $(3 \mu \mathrm{m})$ were deparaffinized and rehydrated, endogenous peroxydase was quenched with $0.6 \% \mathrm{H}_{2} \mathrm{O}_{2}$ and $0.1 \%$ sodium azide (Sigma). Antigen retrieval was done by pressure cooking: slides were bathed in a $10^{-2} \mathrm{M}$ sodium citrate buffer for $3 \mathrm{~min}$. Sections were then incubated overnight at $4^{\circ} \mathrm{C}$ with the corresponding antibody at a concentration of $2 \mu \mathrm{g} / \mathrm{ml}$ after a pre-incubation step of $15 \mathrm{~min}$ in a $1 / 10$ normal swine serum (Dako). Biotynilated anti-rabbit immunogloblin and streptavidin conjugated to horseradish peroxydase were then added. Finally, 3,3'-diaminobenzidine was used for color development, and hemalun was used for counterstaining. 


\section{Results}

Survivin expression was first investigated at the mRNA level using RT-PCR on 76 tumor biopsies. As illustrated in Figure 1A for representative examples, the expected

A

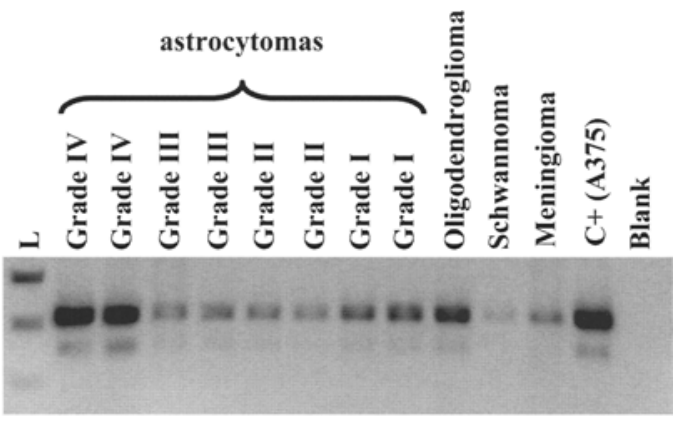

B

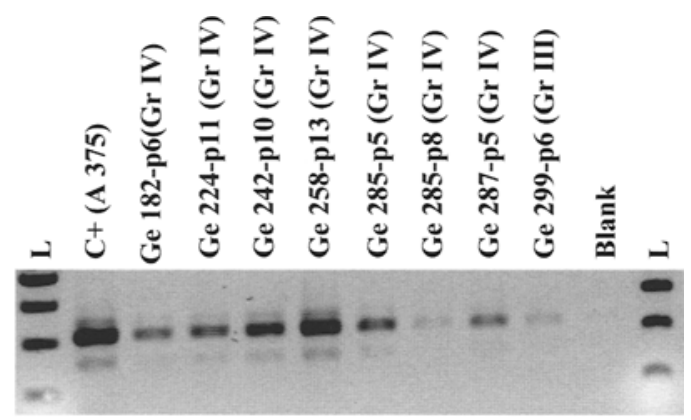

C
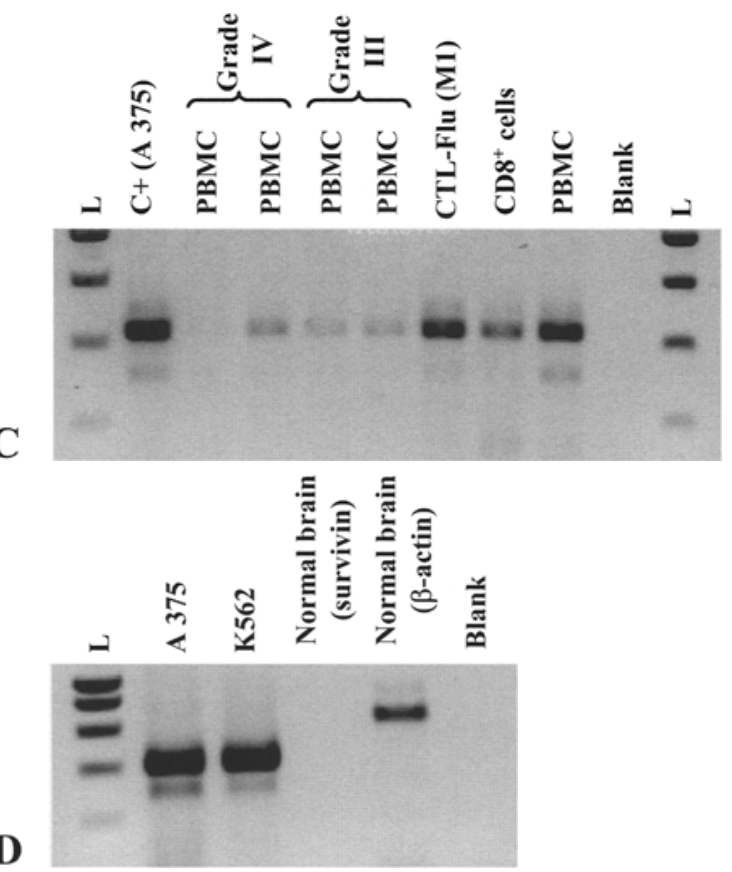

PCR product ( $427 \mathrm{bp}$ ) was obtained in a high proportion of biopsies from all tumor types (Table 1), including meningioma and schwannoma. Survivin mRNA was neither detected in non-tumoral brain (Figure 1D), nor in the contralateral brain hemisphere of tumorburdened patient (data not shown). However, this type of analysis could not discriminate the cell type expressing survivin in vivo. Thus, we analyzed a series of human astrocytoma cell lines and showed that tumor cells express survivin at the mRNA (Figure 1B) and protein (Figure 2A) level.

Recent data by others [13] suggested that activated $\mathrm{T}$ cells might express survivin in some circumstances. The extent to which infiltrating lymphocytes might contribute to the positive signals observed in tumor biopsies was thus an important issue to address. Whilst survivin mRNA was detectable in most PBMC samples from astrocytoma patients and healthy donors (Figure 1C), the protein was not detected by Westernblot analysis (Figure 2B). This indicates that tumor infiltrating lymphocytes play a minor role (if any) in survivin expression by ex vivo samples.

To confirm protein expression by tumor cells, immunohistochemical analysis was performed. As illustrated in Figure 3, we observed positively stained tumor cells in each specimen from all types of human brain tumors analyzed (glioblastoma, grade III astrocytoma, schwannoma, meningioma). Interestingly, positive cells showed atypical nucleus and were larger than lymphocytes, whilst perivascular lymphocytes and hyperplasic endothelia were negative. The number of positively stained cells was highly variable, even among samples with the same histological diagnosis. This indicates that further analyses are required in order to investigate for possible correlation with the tumor type, the histological grade and the clinical outcome of the patients.

\footnotetext{
Figure 1. Analysis of survivin mRNA expression in brain tumor biopsies, astrocytoma cell lines and PBMC and non-tumoral brain tissue. mRNA expression was assessed by RT-PCR. PCR product ( $427 \mathrm{bp}$ ) was verified by sequencing. The melanoma cell line A375 and K562 were used as a positive control. (A) brain tumor samples. (B) tumor cell lines obtained from grade III and grade IV astrocytoma. (C) PBMC from astrocytoma patients and PBMC, CTLs flu (directed against Ml peptide: 58-66) and isolated CD8 ${ }^{+} \mathrm{T}$ cells from an healthy donor (HD). (D) non-tumoral (epileptic) brain sample. Results shown here have been repeated three times. $p$ indicates passage; $L$ indicates the molecular weight ladder.
} 


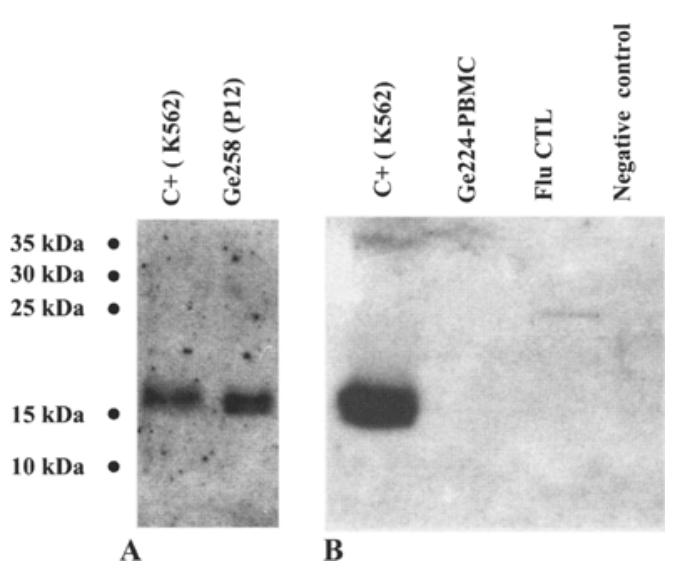

Figure 2. Survivin is expressed by astrocytoma cell lines but not by PBMC from astrocytoma patients and healthy individual. The presence of survivin protein was checked by western blotting in glioblastoma cell lines as illustrated for Ge258 in (A), and in PBMC from glioblastoma patients (Ge224) and from the flu CTLs of an healthy donor (B). K562 cell line was used as a positive control. The negative control used corresponds to one glioblastoma cell line that was found to be RT-PCR negative. Results shown here have been repeated three times.

\section{Discussion}

We have examined the expression of survivin in a large series of human brain tumors. We observed moderate to strong mRNA and protein expression in most biopsies from astrocytomas, oligodendrogliomas, meningiomas and schwannomas (Table 1), whilst no expression was detectable in normal brain (Figure 1D) and [2]. The most relevant finding of this study is the direct demonstration that tumor cells themselves express survivin, as assessed by mRNA and protein analysis of several cell lines and by immunohistochemistry of glioma, meningioma and schwannoma samples. These data confirm and extend the observations recently reported by Chakravarti et al. [12]. In their study, survivin positivity and high protein expression levels were suggested to be of unfavorable prognostic value. However, the method used (i.e. Western-blot) did not identify the cellular source of survivin expression, and it could not be excluded that glioma infiltrating lymphocytes could contribute to the positive Western-blot signals therefore distorting the prognostic factor analysis. Our data, by clearly identifying tumor cells as the main

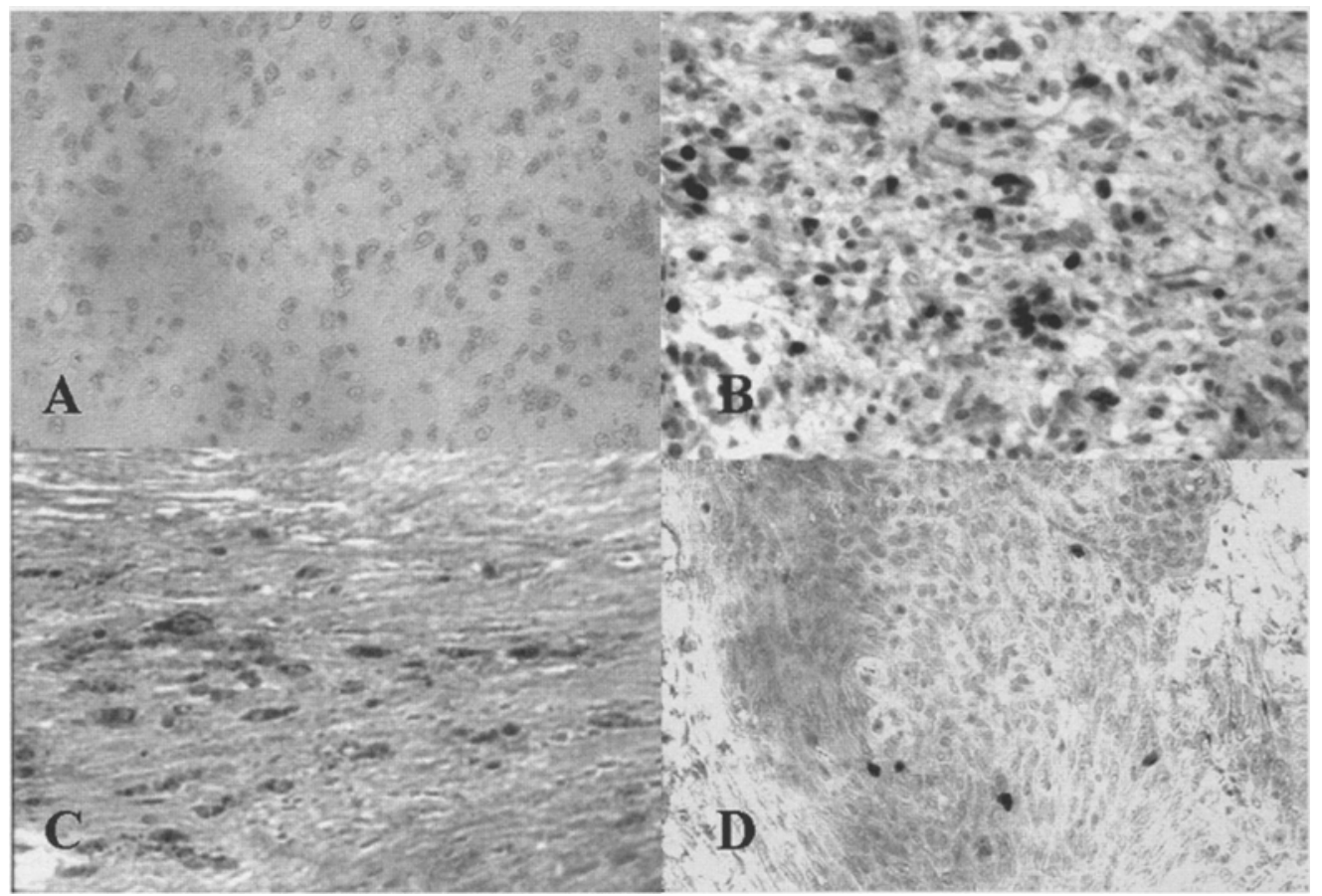

Figure 3. Survivin is expressed by tumor cells in glioblastoma, schwannoma and meningioma. Sections from glioblastoma (A and B), schwannoma (C) and meningioma (D) were stained the rabbit IgG anti-human survivin polyclonal antibody (B-D) or an isotype-matched control $\mathrm{Ab}(\mathrm{A})$. Final magnification: $\times 200$. 
source of survivin expression, provide indirect support to their assessment suggesting that survivin may be an important factor to prevent glioma cell apoptosis.

The prognosis of patients with brain tumors remains dismal despite huge efforts to improve surgical techniques, to use heavy particles for irradiation and to find new drugs. To devise new treatment strategies to target brain tumors is therefore a critical challenge for the next years. For gliomas, a major impediment to the success of therapy is their propensity to infiltrate normal structures, rendering demanding the specific targeting of malignant cells whilst sparing normal cells. Taking advantage of the natural migratory properties of immune cells and their anti-tumor activities, the fine manipulation of the immune system appears now as a promising new treatment avenue [15]. However, the specific targeting of tumor cells requires the characterization of the antigens that can be recognized by immune cells. For brain neoplasia, this research field is far less advanced than for melanoma. A few candidates have been suggested, but their real capabilities to elicit an immune response have rarely been explored $[16,17]$. Considering its widespread expression pattern that we and others [12] have reported, survivin seems to be an interesting candidate to be examined. Indeed, its immunogenic properties have recently been evidenced in patients with non-CNS tumors. First, antibody reactivity against survivin was shown in the sera from some patients with lung or colorectal cancer [18]. Second, it was possible to generate in vitro survivin-specific CD8+ effector cells, and HLA-A2 restricted epitopes that are naturally processed have been identified [19]. Third, in an elegant series of experiments using multimeric survivin peptide/MHC complexes, Anderson et al. [20] showed spontaneous MHC-restricted response against survivin epitopes both in situ and ex vivo in breast cancer, leukemia and melanoma patients. Finally, the same authors reported that survivin specific $T$ cells isolated by magnetic beads coated with multimers were able to lyse HLA-matched tumors originating form diverse tissue types [21].

Overall, these data indicate that the eliciting or reinforcement of specific immune response against survivin is a promising approach for immunotherapies designed for brain tumors. However, the clinical development should be performed with caution, considering recent results showing that survivin may also be expressed in activated $\mathrm{T}$ cells, $\mathrm{CD} 34^{+}$cells, as well as stem cell populations that are involved in the renewal process of normal human colonic mucosa $[2,13,22,23]$.

\section{Acknowledgements}

This work was supported by la Fondation Lionel Perrier and la Fondation Dinu-Lipatty.

\section{References}

1. Altieri DC, Marchisio PC, Marchisio C: Survivin apoptosis: an interloper between cell death and cell proliferation in cancer. Lab Invest 79: 1327-1333, 1999

2. Ambrosini G, Adida C, Altieri DC: A novel anti-apoptosis gene, survivin, expressed in cancer and lymphoma. Nature Med 8(3): 917-921, 1997

3. Monzo M, Rosell R, Felip E, Astudillo J, Sanchez JJ, Maestre J, Martin C, Font A, Barnadas A, Abad A: A novel anti-apoptosis gene: re-expression of survivin messenger RNA as a prognosis marker in non-small-cell lung cancers. J Clin Oncol 17: 2100-2104, 1999

4. Xing N, Qian J, Bostwick D, Bergstralh E, Youg CY: Neuroendocrine cells in human prostate over-express the antiapoptosis protein survivin. Prostate 48: 7-15, 2001

5. Grossman D, McNiff JM, Li F, Altieri DC: Expression of the apoptosis inhibitor, survivin, in nonmelanoma skin cancer and gene targeting in a keratinocyte cell line. Lab Invest 79: 1121-1126, 1999

6. Kawasaki H, Altieri DC, Lu CD, Toyoda M, Tenjo T, Tanigawa N: Inhibition of apoptosis by survivin predicts shorter survival rates in colorectal cancer. Cancer Res 58 : 5071-5074, 1998

7. Satoh K, Kaneko K, Hirota M, Masamune A, Satoh A, Shimosegawa T: Expression of survivin is correlated with cancer cell apoptosis and is involved in the development of human pancreatic duct cell tumors. Cancer 92(2): 271-278, 2001

8. Tanaka $\mathrm{K}$, Iwamoto $\mathrm{S}$, Gon $\mathrm{G}$, Nohara $\mathrm{T}$, Iwamoto $\mathrm{M}$, Tanigawa N: Expression of survivin and its relationship to loss of apoptosis in breast carcinomas. Clin Cancer Res 6: 127-134, 2000

9. Lu CD, Altieri DC, Tanigawa N: Expression of a novel antiapoptosis gene, survivin, correlated with tumor cell apoptosis and $\mathrm{p} 53$ accumulation in gastric carcinomas. Cancer Res 58: 1808-1812, 1998

10. Kato J, Kuwabara Y, Mitani M, Shinoda N, Sato A, Toyama T, Mitsui A, Nishiwaki T, Moriyama S, Kudo J, Fujii Y: Expression of survivin in esophageal cancer: correlation with the prognosis and response to chemotherapy. Int J Cancer 95: 92-95, 2001

11. Adida C, Haioun C, Gaulard P, Lepage E, Morel P, Briere J, Dombrel H, Reyes F, Diebold J, Gisselbrecht C, Salles G, Altieri DC, Molina TJ: Prognostic significance of survivin expression in diffuse large B-cell lymphomas. Blood 96: 1921-1925, 2000

12. Chakravarti A, Noll E, Black PM, Finkelstein DF, Finkelstein DM, Dyson NJ, Loeffler JS: Quantitatively determined survivin expression levels are of prognostic value in human gliomas. J Clin Oncol 20: 1063-1068, 2002 
13. Sharief MK, Semra YK: Heightened expression of survivin in activated $\mathrm{T}$ lymphocytes from patients with multiple sclerosis. J Neuroimmunol 119: 358-364, 2001

14. Saas $P$, Walker PR, Hahne M, Quiquerez AL, Schnuriger V, Perrin G, French L, Van Meir EG, de Tribolet N, Tschopp J, Dietrich PY: Fas ligand expression by astrocytoma in vivo: maintaining immune privilege in the brain? J Clin Invest 99(6): 1173-1178, 1997

15. Hösli P, Sappino AP, de Tribolet N, Dietrich PY: Malignant glioma: should chemotherapy be overthrown by experimental treatments? Ann Oncol 9: 589-600, 1998

16. Imaizumi $T$, Kuramoto $T$, Matsunaga $K$, Shichijo $S$, Yutani S, Shigemori M, Oizumi K, Itoh K: Expression of the tumor-rejection antigen SARTI in brain tumors. Int $J$ Cancer 83(6): 760-764, 1999

17. Heimberger AB, Archer GE, Crotty LE, McLendon RE, Friedman AH, Friedman HS, Bigner DD, Sampson JH: Dendritic cells pulsed with a tumor-specific peptide induce long-lasting immunity and are effective against murine intracerebral melanoma. Neurosurgery 50: 158-166, 2002

18. Rohayem J, Diestelkoetter P, Weigle B, Oehmichen A, Schmitz M, Mehlhorn J, Conrad K, Rieber EP: Antibody response to the tumor-associated inhibitor of apoptosis protein survivin in cancer patients. Cancer Res 60: 4515-4817, 2000

19. Schmitz M, Diestelkoetter P, Weigle B, Schmachtenberg F, Stevanovic S, Ockert D, Rammensee H-G, Rieber EP: Generation of survivin-specific $\mathrm{CD}^{+} \mathrm{T}$ effector cells by dendritic cells pulsed with protein or selected peptides. Cancer Res 60: 4845-4849, 2000

20. Andersen MH, Pedersen LO, Capeller B, Brocker E-B, Becker JC, Straten Pt: Spontaneous cytotoxic T-cell responses against survivin-derived $\mathrm{MHC}$ class I-restricted T-cell epitopes in situ. As well as ex vivo in cancer patients. Cancer Res 61: 5964-5968, 2001

21. Andersen MH, Pedersen LO, Becker JC, Straten Pt: Identification of a cytotoxic $T$ lymphocyte response to the apoptosis inhibitor protein survivin in cancer patients. Cancer Res 61: 869-872, 2000

22. Adida C, Crotty PL, McGrath J, Berrebi D, Diebold J, Altieri DC: Developmentally regulated expression of the novel cancer anti-apoptosis gene survivin in human and mouse differentiation. Am J Pathol 152: 43-49, 1998

23. Fukuda S, Pelus M: Regulation of the inhibitor-of-apoptosis family member survivin in normal cord blood and bone marrow CD34+ cells by hematopoietic growth factors: implication of survivin expression in normal hematopoiesis. Blood 98: 2091-2100, 2001

Address for offprints: Pierre-Yves Dietrich, Hôpital Cantonal de Genève, Division d'oncologie, Laboratoire d'immunologie des tumeurs, 24 Rue Micheli du Crest, 1211 Geneve 14, Switzerland; Tel.: 41-22-372-98-61; Fax: 41-22-372-98-58; E-mail: pierreyves.dietrich@hcuge.ch 